\title{
The Implications of Two German Price Zones in a European-Wide Context
}

\author{
Glenn Plancke, Cedric De Jonghe and Ronnie Belmans \\ KU Leuven, EnergyVille \\ Leuven, Belgium
}

\begin{abstract}
As German TSOs are faced with the threat of northsouth transmission line overloading, the option of a national bidding zone reconfiguration in the form of a separate northern and southern bidding zone is investigated. By imposing a limit on north-south transactions during market clearing, less redispatch actions are necessary afterwards, as such resulting in more efficient congestion management. However, through market coupling, a national bidding zone reconfiguration also has an impact on neighbouring electricity markets. This paper analyzes the altered interactions between electricity markets caused by the introduction of two German prices zones by means of a costminimizing dispatch model. Besides modifying the market outcome within Germany, this market design change also impacts consumers and producers in other European countries. Therefore, a national bidding zone reconfiguration should always be analyzed in a European wide context.
\end{abstract}

Index Terms-Available Transfer Capacities, bidding zones, congestion management, electricity markets, market coupling

\section{INTRODUCTION}

Historically, European countries focused on selfsufficiency in terms of power supply. Developing the internal transmission network was prioritized over the development of interconnection capacity. Consequently, the current European power system is operated based on a zonal pricing mechanism in accordance with national borders. Zonal pricing is a simplification of the theoretically preferred approach of nodal pricing, where locational marginal prices (LMPs) are determined for each separate node of the network [1]-[4]. Under zonal pricing, nodes are aggregated into zones, disregarding internal network constraints.

A crucial assumption of zonal pricing though is that network capacity bottlenecks coincide with zonal borders [5]. Hence, internal congestion inside a bidding zone is assumed insignificant. However, two important trends challenge the present zonal configuration in Europe. Intensified cross-border trade and the rising share of renewable energy sources result in an increasing amount of volatile and unpredictable power flows on the transmission network. Therefore, internal congestion occurs more commonly, increasingly demanding for redispatch actions by the Transmission System Operator (TSO). German TSOs frequently face the threat of north-south transmission line overloading, caused by the spatial imbalance between supply and demand [6]. A significant share of renewables integration occurs in the north, compared to the south of Germany. The total volume of redispatch actions in Germany increased by $160 \%$ in 2015 compared to $2014^{1}$. As an alternative to an elevated redispatch cost, the introduction of additional price zones in the form of one northern and one southern zone is investigated in order to reduce pressure on the current German electricity system.

This paper implements a cost-minimizing dispatch model to investigate the implications of a national bidding zone reconfiguration in a European-wide context. One uniform German bidding zone is compared to a market design with two German price zones. Because of market coupling, a national bidding zone reconfiguration also influences market outcomes in other European countries. More specifically, this paper highlights to which extent the split-up of the German electricity market alters bilateral interactions between European electricity markets. The modified market outcome in Germany is analyzed, as well as the implications for consumers and producers in other European countries.

Section II provides an overview of the literature on congestion management and explains why the introduction of additional bidding zones leads to more efficient congestion management. Section III elaborates on the research method, sequentially describing the implemented spot market model and the used input data. Obtained results are presented in section IV. Section V concludes.

\section{Congestion Mangement}

The transmission network impacts the operation of a power system. While several transmission constraints can be distinguished, capacity constraints occupy a prominent place in literature. These constraints limit the electric power that can be transported between any two points in the grid. As a result, congestion - a situation in which the electricity network cannot accommodate all scheduled transactions - may occur [7]. Congestion management can be defined as all actions taken to avoid or relieve congestions in the electricity grid [8]. Deterrent (ex-ante) and corrective (ex-post) congestion management techniques can be distinguished [9]. While the former attempt to schedule generation prior to operation in such a way as to avoid congestion, corrective techniques influence generation at the time of operation to relieve congestion. Deterrent congestion management techniques can be classified according to a nodal and zonal pricing mechanism. 


\section{A. Nodal Pricing}

Nodal pricing is often put forward as the most efficient transmission pricing mechanism [1]-[4]. This system is applied among regions worldwide, most notably in the PJM interconnection, ERCOT, New York and New England markets in the US, New Zealand, Singapore and Russia.

Nodal pricing, more appropriately referred to as locational marginal pricing (LMP), determines separate prices for each node of the network. Besides an energy component, these prices also reflect transmission constraints. The locational marginal price is the marginal cost of supplying the next increment of electric energy at a specific bus considering the generation marginal cost and the physical aspects of the transmission system [10]. Price differences between nodes reflect the cost of transmission [11]. When all transmission constraints are accurately incorporated into nodal prices, there is no need for corrective congestion management actions. While the theoretical principles of LMP are clear, practical implementations of nodal pricing models differ [12]. For example, the extent to which generators and retailers (or both) are subject to nodal prices, deviates. Also a financial as opposed to a physical approach concerning risk management to hedge against volatile real-time nodal prices can be identified. Finally, some markets, e.g. in the US, are organized with an Independent System Operator (ISO) who is not the transmission system owner. This contrasts markets with Transmission System Operators (TSOs) which both own and operate the system. As such, there exists no one predefined implementation of nodal pricing.

\section{B. Zonal Pricing}

On the other hand, not all developed electricity markets in the world have adopted a nodal pricing mechanism. Europe in particular is still operated based on a zonal configuration. Furthermore, a move towards nodal pricing is not foreseen in the near future, as the Target model put forward by ENTSO-e does not encompass such a consideration. Instead, an assessment of the efficiency of the current bidding zone configuration will be carried out every two years [13].

Under zonal pricing, individual network nodes are aggregated into zones which constitute uniform price areas. In Europe, the integration of the separate markets is done through market coupling, where transactions between zones are allowed up to a predefined Available Transfer Capacity (ATC) level ${ }^{2}$. The European electricity model essentially separates the energy and transmission market, as follows: First, TSOs determine appropriate ATCs between zones. Second, the energy market is cleared - within the limits of the ATCs - by Power Exchanges (PXs) which act as market operators. Afterwards, TSOs take the necessary corrective congestion management actions to ensure a safe and secure operation of the transmission network. While a "right ATC" can make market coupling relatively efficient compared to nodal pricing, selecting the right ATC is, and will probably remain, an unsolved issue [5]. Besides determining the appropriate ATCs, another option to more accurately represent the transmission network is to geographically redefine the actual price zones. Introducing additional price zones results in a more refined representation of the transmission grid at the market clearing stage. As such, the likelihood of binding transmission constraints within a zone, and thus the need for corrective congestion management, is reduced. Furthermore, smaller price zones also decrease uncertainty about generation and load patterns within a zone, allowing for a less reserved determination of ATCs [14]. The European Network codes on "Capacity Allocation and Congestion Management" formulated by ENTSO-e prescribe to define bidding zones such that they ensure efficient congestion management and lead to overall market efficiency. Moreover, the bidding zone configuration should be consistent across all timeframes and stable over time [13].

Due to market coupling, European electricity markets interact. Therefore, a national bidding zone reconfiguration also influences market outcomes in other European countries. This paper complements literature by analyzing to which extent electricity market interactions in a zonal ATC system are impacted by the introduction of two German price zones. Besides studying the altered market outcome within Germany, also the implications for consumers and producers in other European countries are investigated.

\section{RESEARCH METHOD}

A cost-minimizing dispatch model is applied to simulate market clearing in the spot market, taking into account market coupling across Europe under a zonal pricing approach [6]. The implemented model is a variation on the ELMOD model, which is developed at the Dresden University of Technology in order to analyze various questions on market design, congestion management and investment decisions, with a focus on Germany and continental Europe ${ }^{3}$ [15]. The model has previously been used to analyze topics concerning network expansion and the integration of renewables, approaches to incorporate network constraints into market clearing and coordination aspects regarding congestion management and dispatch [16]-[19].

\section{A. Spot Market Model}

Market clearing is performed by a market operator who maximizes social welfare. The simple spot market model used in this paper abstracts from complications such as block bids and assumes a perfectly competitive market. Furthermore, perfectly inelastic demand curves per country are implemented. The generation cost-minimizing objective function is first of all subject to a general zonal power balance equation. This equation states that electricity generation within each zone, supplemented by import, must be in balance with electricity demand and export. Further constraints restrict renewable outputs per technology, impose limitations on the generation output for every conventional power plant and control for ramping rates. Ramping rates typically express flexibility as a percentage of the total installed capacity of a generation unit. Since this flexibility depends on the operating point of a power

${ }^{2}$ With the exception of the day-ahead market in Central Western

${ }^{3}$ ELMOD website: www.diw.de/elmod 
plant, a distinction is made between committed and noncommitted capacity [20]. Pumped-storage hydro plants are represented through limitations for power release and loading, boundaries on the stored energy level and a description of the law of motion. Finally, commercial exchanges of power between countries are allowed up to a predefined ATC level.

\section{B. Input Data}

The spot market model is solved for a 2020 scenario in 53 weekly blocks. The spatial scope of the model encompasses 36 European countries, stretching from Portugal in the south until Finland in the north. Interactions between electricity markets are modelled using the ATC approach. ATC values are derived for both directions on all borders, based on historical data while at the same time taking into account new investments in interconnection capacity towards 2020 .

The German electricity market is modeled on the level of individual power plants [6]. This is in contrast with other European countries, for which only aggregate capacities per technology are available. Demand and renewables information is denoted per country and takes into account seasonal availability factors. For Germany in particular, this data is split up according to the investigated north-south breakdown (see also fig. 4) [6]. Annual demand in the northern zone (370TWh) is significantly higher than in the southern zone (173TWh). North-south power exchanges in both directions within Germany are allowed up to a defined ATC limit of 8GW [6]. For a 2020 scenario, in both the northern and southern zone, the sum of the installed renewable generation capacities is higher than the sum of all conventional generation capacities. This is mainly due to high shares of onshore wind and solar PV in the north, and solar PV in the south. Compared to 2015, the total conventional generation capacity decreases, while the installed renewable generation capacity is significantly increased. The installed onshore wind generation capacity in the north of Germany is expanded by at least $13 \mathrm{GW}$. In 2020, some nuclear power plants are already shut down, as part of the planned nuclear phase-out in Germany towards 2022.

\section{RESULTS}

This chapter analyzes the implications of the introduction of a separate northern and southern price zone in Germany. First of all, the modified market outcome within Germany is investigated. Secondly, the main flow deviations through Germany's neighbouring electricity markets are studied. A final section discusses the impact on consumers and producers across Europe separately.

\section{A. Implications for Germany}

North-south power exchanges in Germany are driven by price differences between the newly introduced northern and southern price zone and restricted by an exchange limit. An ATC level of $8 \mathrm{GW}$ is determined for both directions between the two zones [6]. In case of north-south congestion, price differences arise. This section sequentially discusses northsouth power exchanges and price divergence within Germany.

\section{1) North-south Power Exchanges}

By introducing two German price zones, interactions between the north and south of Germany are now included in the market clearing step. Exchanges between the northern and southern price zone in Germany are represented by black bars in fig. 1. Positive (negative) values correspond with an exchange from south to north (north to south). From this figure, it is clear that strong north-south exchanges within Germany occur for a 2020 scenario. The ATC limit of $8 \mathrm{GW}$ for northsouth transactions is reached in $60 \%$ of the time. Furthermore, a seasonal effect during summer can be observed. As the availability of solar PV generation in the south of Germany increases during summer, the need for north-south transportation of electric energy is temporarily diminished.

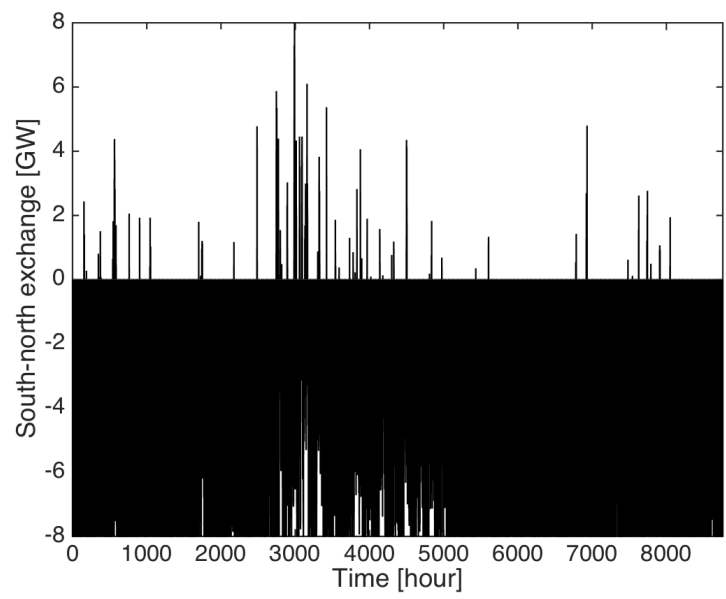

Figure 1: North-south (negative values) and south-north (positive values) exchanges in Germany

\section{2) North-south Price Divergence}

Together with dominant north-south power exchanges, price divergence between the southern and northern German price zone occurs (fig. 2). The maximum instantaneous southnorth price spread equals 48,85EUR/MWh, while the weighted average spread for 2020 is equal to 5,16EUR/MWh. However, price convergence still occurs in $50 \%$ of the time. Remarkably, the price in the north is never higher than the price in the south in 2020 .

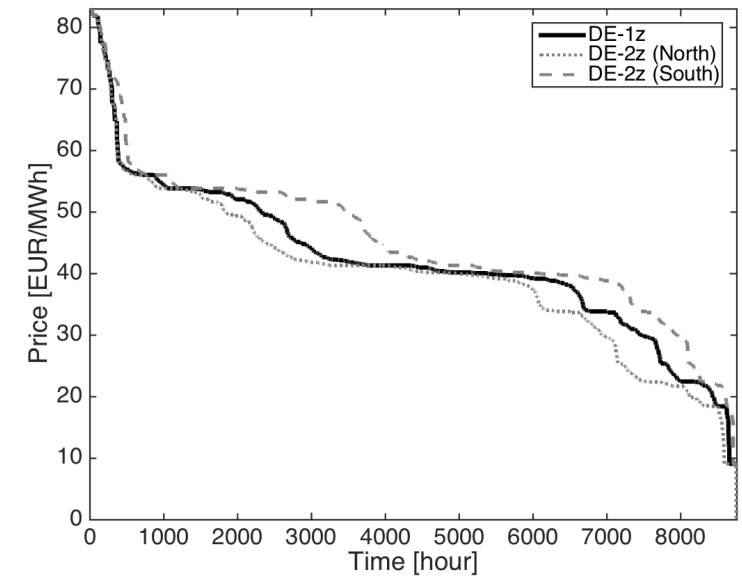

Figure 2: Price duration curve [Germany 1 zone vs. Germany 2 zones] 


\section{B. Implications for Cross-border Commercial Flows}

Due to market coupling, European electricity markets interact. When north-south transactions within Germany are restricted by an exchange limit, part of this obstructed commercial flow will find another path.

Fig. 3 displays the main impacted borders. Black (grey) bars indicate the percentage of time power flows in the defined (reverse) direction. With two German price zones, German imports from Austria are considerably increased. Three main deviations towards the south of Germany via Austria can be distinguished (fig. 3 and 4). First of all, commercial flows from the Czech Republic (CZ) towards Austria (AT) occur more frequently (1). Secondly, also more regular exchanges from Slovakia (SK) to Hungary (HU) and then towards Austria take place (2). Finally, a new path from Hungary through Croatia (HR) and Slovenia (SI), eventually arriving again in Austria, can be identified as well (3).

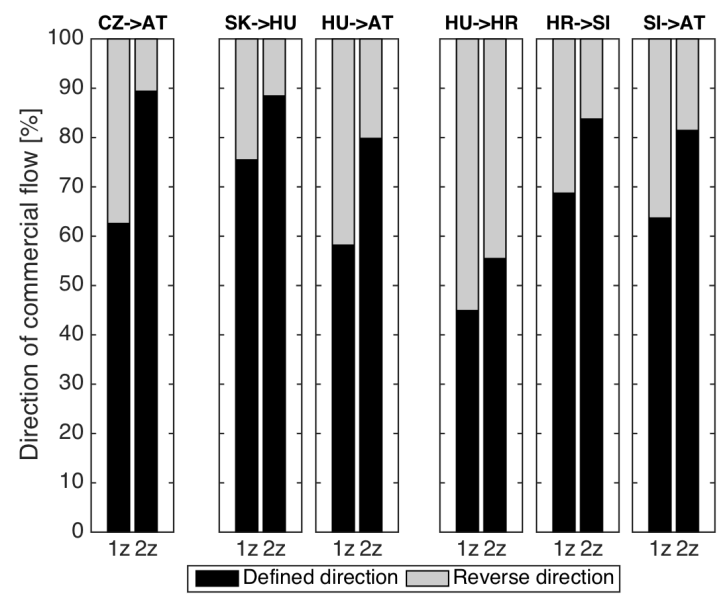

Figure 3: Main impacted cross-border commercial flows [Germany 1 zone (1z) vs. Germany 2 zones (2z)]

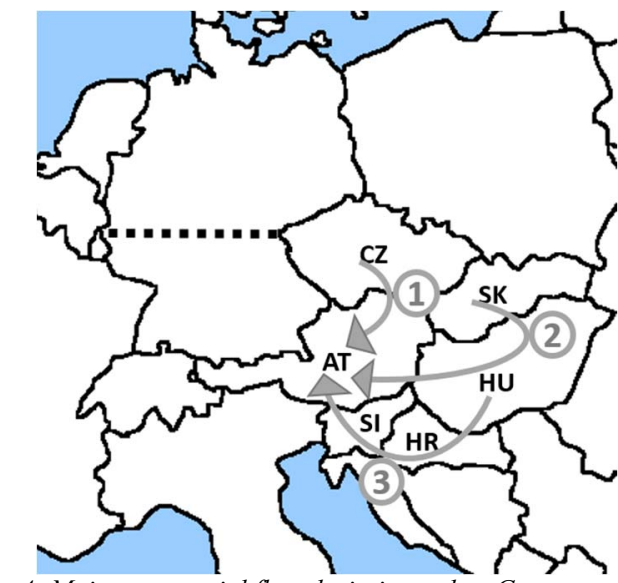

Figure 4: Main commercial flow deviations when Germany evolves to two price zones

\section{Implications for Consumers and Producers across Europe}

Because of market coupling, a national bidding zone reconfiguration influences market outcomes in other European countries. Since the altered cross-border commercial flows provide only part of the picture, this section analyzes in detail the implications of two German price zones for consumers and producers separately.

\section{1) Consumers}

Despite the implementation of a perfectly inelastic demand curve for each country, consumer surpluses can be derived by considering a Value of Lost Load (VOLL). As such, consumer surplus corresponds with the difference between the VOLL and the market price, multiplied by the fixed energy demand in this country. The change in consumer surplus when Germany evolves from one bidding zone towards two separate price zones is presented in fig. 5. Mainly consumers in the north of Germany are better off. However, a positive impact on consumer surplus is also noticeable for Sweden, Norway and Poland. On the other hand, primarily consumers in the South of Germany, as well as French and Austrian consumers, are worse off. Overall, consumers in Germany benefit from two German price zones, as the positive impact on consumers in the north (+783 million EUR) outweighs the decrease in consumer surplus for the southern region (-527 million EUR).

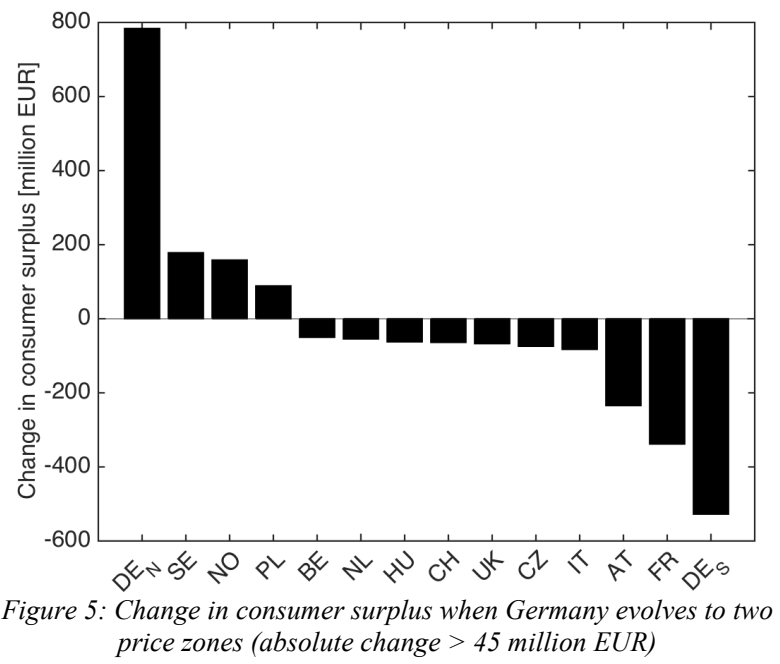

\section{2) Producers}

Fig. 6 displays the change in producer surplus per country when Germany evolves from one bidding zone to two separate price zones. Producer surplus is defined as the sum of the differences between the market price paid for a unit of energy and the marginal cost to produce this unit. Producer surplus is crucially influenced by the amount of electric energy that is generated locally. Local generation is determined by domestic energy demand, augmented by net exports. Main increases in producer surplus take place in the south of Germany, France and Austria. In contrast, producer surplus is reduced drastically in the north of Germany, but also in Sweden and Norway. In total, German producers are worse off with two German price zones, as producer surplus decreases by 1030 million EUR in the north, while an increase of only 438 million EUR occurs in the south. 


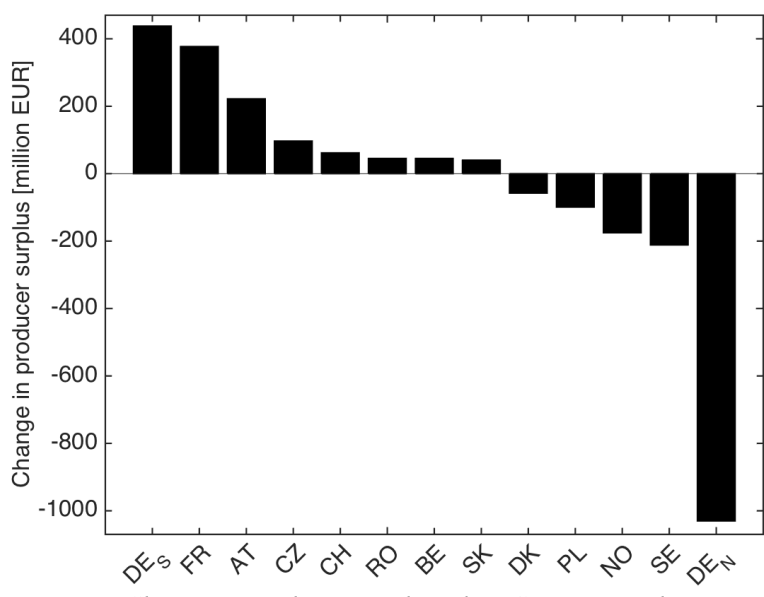

Figure 6: Change in producer surplus when Germany evolves to two price zones (absolute change $>40$ million EUR)

\section{CONCLUSION}

Faced with north-south congestion, Germany investigates the option of a national bidding zone reconfiguration. The German transmission network is better represented in the market clearing step when a separate northern and southern price zone exist. By imposing a limit on north-south transactions during market clearing, less redispatch actions are required afterwards.

However, through market coupling, a national bidding zone reconfiguration impacts other European electricity markets as well. This paper shows that such a market design change should be analyzed in a European wide context. First of all, a limitation on transactions from north to south within Germany results in a deviation of commercial flows through neighbouring countries located south-east of Germany. Furthermore, consumers and producers across European countries are impacted. Within Germany, consumers are better off with two price zones, while the producers lose. Interestingly, considerable changes in consumer and producer surpluses for Germany's neighbouring countries can be observed as well.

Nevertheless, to decide on the desirability of two separate German price zones it is necessary to perform a global welfare analysis. First of all, the reduction in redispatch cost within Germany has to be quantified. Moreover, the overall change in congestion rent should be taken into account. Congestion rent, calculated as the sum of the price differences between zones multiplied by the commercial flow between the zones, is an ownerless income collected by the market operator and contributes to the overall social welfare.

\section{REFERENCES}

[1] M. C. Caramanis, R. E. Bohn, and F. C. Schweppe, "Optimal Spot Pricing: Practice and Theory," IEEE Trans. Power Appar. Syst., vol. PAS-101, no. 9, pp. 3234-3245, 1982.

[2] W. W. Hogan, "Transmission Congestion: The Nodal-Zonal Debate Revisited," Harvard Univ. John F. Kennedy Sch. Gov. Cent. Bus. Gov. Retrieved August, vol. 29, p. 2005, 1999.

[3] W. W. Hogan, "Contract networks for electric power transmission," J. Regul. Econ., vol. 4, no. 3. pp. 211-242,
1992.

[4] M. Hsu, "An introduction to the pricing of electric power transmission," Util. Policy, vol. 6, no. 3, pp. 257-270, 1997.

[5] G. Oggioni and Y. Smeers, "Market failures of Market Coupling and counter-trading in Europe: An illustrative model based discussion," Energy Econ., vol. 35, pp. 74-87, 2013.

[6] J. Egerer, J. Weibezahn, and H. Hermann, "Two Price Zones for the German Electricity Market - Market Implications and Distributional Eff ects," 2015.

[7] H. Knops, L. De Vries, and R. Hakvoort, "Congestion management in the European Electricity System: An evaluation of the alternatives," J. Netw. Ind., vol. 1, 2001.

[8] A. Kumar, S. C. Srivastava, and S. N. Singh, "Congestion management in competitive power market: A bibliographical survey," Electr. Power Syst. Res., vol. 76, no. 1-3, pp. 153164, 2005.

[9] R. D. Christie, B. F. Wollenberg, and I. Wangensteen, "Transmission management in the deregulated environment," Proc. IEEE, vol. 88, no. 2, pp. 170-195, 2000.

[10] M. Shahidehpour, H. Yamin, and Z. Li, Market Operations in electric power systems. 2002.

[11] F. Leuthold, H. Weigt, and C. von Hirschhausen, "Efficient pricing for European electricity networks - The theory of nodal pricing applied to feeding-in wind in Germany," Util. Policy, vol. 16, no. 4, pp. 284-291, 2008.

[12] F. E. Pettersen, L. Ekern, and V. Willumsen, "Mapping of selected markets with Nodal pricing or similar systems. Australia, New Zealand and North American power markets," Norwegian Water Resources and Energy Directorate, Feb. 2011.

[13] European Commission, "Commission Regulation on establishing a guideline on Capacity Allocation and Congestion Management," 2014.

[14] K. Neuhoff, S. Ruester, and S. Schwenen, "Power Market Design beyond 2020: Time to Revisit Key Elements?," DIW Berlin, Discussion paper, 2015.

[15] F. Leuthold, H. Weigt, and C. von Hirschhaussen, "Electricity Markets Working Papers ELMOD - A Model of the European Electricity Market," TU Dresden, Jul. 2008.

[16] F. Kunz and A. Zerrahn, "Benefits of coordinating congestion management in electricity transmission networks: Theory and application to Germany," Util. Policy, vol. 37 , pp. 34-45, 2015.

[17] F. Kunz, "Improving congestion management: How to facilitate the integration of renewable generation in Germany," Energy J., vol. 34, no. 4, pp. 55-78, 2013.

[18] K. Neuhoff, J. Barquin, J. W. Bialek, R. Boyd, C. J. Dent, F. Echavarren, T. Grau, C. von Hirschhausen, B. F. Hobbs, F. Kunz, C. Nabe, G. Papaefthymiou, C. Weber, and H. Weigt, "Renewable electric energy integration: Quantifying the value of design of markets for international transmission capacity," Energy Econ., vol. 40, pp. 760-772, 2013.

[19] H. Weigt, T. Jeske, F. Leuthold, and C. von Hirschhausen, “"Take the long way down': Integration of large-scale North Sea wind using HVDC transmission," Energy Policy, vol. 38, no. 7, pp. 3164-3173, 2010.

[20] C. De Jonghe, E. Delarue, R. Belmans, and W. D'haeseleer, "Determining optimal electricity technology mix with high level of wind power penetration," Appl. Energy, vol. 88, no. 6, pp. 2231-2238, 2011. 